\title{
Metal oxide nanocage as drug delivery systems for Favipiravir, as an effective drug for the treatment of COVID-19: a computational study
}

\author{
Chunchun $\mathrm{Yao}^{1} \cdot$ Feng Xiang $^{1} \cdot$ Zhangyi Xu$^{1}$
}

Received: 13 December 2021 / Accepted: 10 February 2022 / Published online: 18 February 2022

(c) The Author(s), under exclusive licence to Springer-Verlag GmbH Germany, part of Springer Nature 2022

\begin{abstract}
This paper is a summary of research that looks at the potential of fullerene-like (MO) ${ }_{12}$ nanoclusters (NCs) in drug-carrying systems using density functional theory. Favipiravir $/ \mathrm{Zn}_{12} \mathrm{O}_{12}(-34.80 \mathrm{kcal} / \mathrm{mol})$, Favipiravir $/ \mathrm{Mg}_{12} \mathrm{O}_{12}(-34.98 \mathrm{kcal} / \mathrm{mol})$, and Favipiravir $/ \mathrm{Be}_{12} \mathrm{O}_{12}(-30.22 \mathrm{kcal} / \mathrm{mol})$ were rated in order of drug adsorption degrees. As a result, Favipiravir attachment to $(\mathrm{MgO})_{12}$ and $(\mathrm{ZnO})_{12}$ might be simple, increasing Favipiravir loading efficiency. In addition, the quantum theory of atoms in molecules (QTAIM) assessment was utilized to look at the interactions between molecules. The FMO, ESP, NBO, and $\mathrm{E}_{\mathrm{ads}}$ reactivity patterns were shown to be in excellent agreement with the QTAIM data. The electrostatic properties of the system with the biggest positive charge on the $M$ atom and the largest $E_{a d s}$ were shown to be the best. This system was shown to be the best attraction site for nucleophilic agents. The findings show that $(\mathrm{MgO})_{12}$ and $(\mathrm{ZnO})_{12}$ have great carrier potential and may be used in medication delivery.
\end{abstract}

Keywords Drug delivery $\cdot$ Fullerene $\cdot$ Nucleophilic $\cdot$ Density functional theory

\section{Introduction}

COVID-19, a new coronavirus, has spread practically everywhere on the globe since late 2019 , generating a plethora of serious public health problems [1]. Due to the lack of an antiviral medication that has been authorized, many efforts have been undertaken to investigate pharmaceutical substances for the supportive therapy of the illness [2]. It is critical to look at current drugs as well as novel compounds to determine whether there's a method to treat COVID-19 swiftly. The structure of COVID-19's protease was first discovered in early 2020 [3], spurring a substantial investigation into the efficacy of current, comparable medications on enzymatic activity [4]. In addition, identifying the mechanism of action of the ligand-target complex is crucial for moving further in the phases of drug development and design [5-8]. Favipiravir has recently been investigated as a potential COVID-19 therapy, and it has been indicated

Zhangyi Xu

yusijie5963349@163.com

1 Department of Pharmacy, Hospital of Wenzhou Medical University, Wenzhou 325000, Zhejiang, China as a viable option. The development of efficient medicine delivery systems has received a lot of attention recently. As a consequence, nanomaterials are now often utilized to characterize novel drug delivery (DD) methods [5-9]. DD materials include zero-dimensional nanoclusters (NCs), onedimensional nanotubes, and two-dimensional nanosheets [10-20]. Theoretical investigations have been undertaken on fullerene-like $(\mathrm{AB})_{12}(\mathrm{~A}=\mathrm{Mg}, \mathrm{Al}, \mathrm{B} \ldots$ and $\mathrm{B}=\mathrm{N}, \mathrm{P}$, $\mathrm{O} . .$.$) NCs as more stable cages than other types of (\mathrm{AB})_{\mathrm{x}}$ structures such as nanosheets and nanotubes [21-40].

Th-symmetrical metal oxide $\mathrm{NCs}$, such as $(\mathrm{MgO})_{12}$, $(\mathrm{BeO})_{12}$, and $(\mathrm{ZnO})_{12}$, have also gotten a lot of interest because of their unique features.

Previous studies have demonstrated that $(\mathrm{BeO})_{12}$ is thermally stable, suggesting that it might be synthesized in this manner [41]. Haertelt and coworkers [42] used density functional theory (DFT) and IR spectroscopy to demonstrate the $(\mathrm{MgO})_{12} \mathrm{NCs}^{\prime}$ stability. In contrast to $(\mathrm{BeO})_{12}$ and $(\mathrm{MgO})_{12}$ $\mathrm{NCs},(\mathrm{ZnO})_{12} \mathrm{NCs}$ have been extensively investigated for their prominent roles in biomedical, gas detector, optoelectronics applications, and as a catalyst [43-54]. Furthermore, $(\mathrm{ZnO})_{\mathrm{x}}$ nanocages have proven outstanding efficacy in $\mathrm{DD}$ applications due to their improved biocompatibility and reduced cost. The $\mathrm{Zn}_{12} \mathrm{O}_{12} \mathrm{NC}$ was successfully synthesized 
Fig. 1 The optimized structures of Favipiravir drug and intact $(\mathrm{MO})_{12} \mathrm{NCs}$

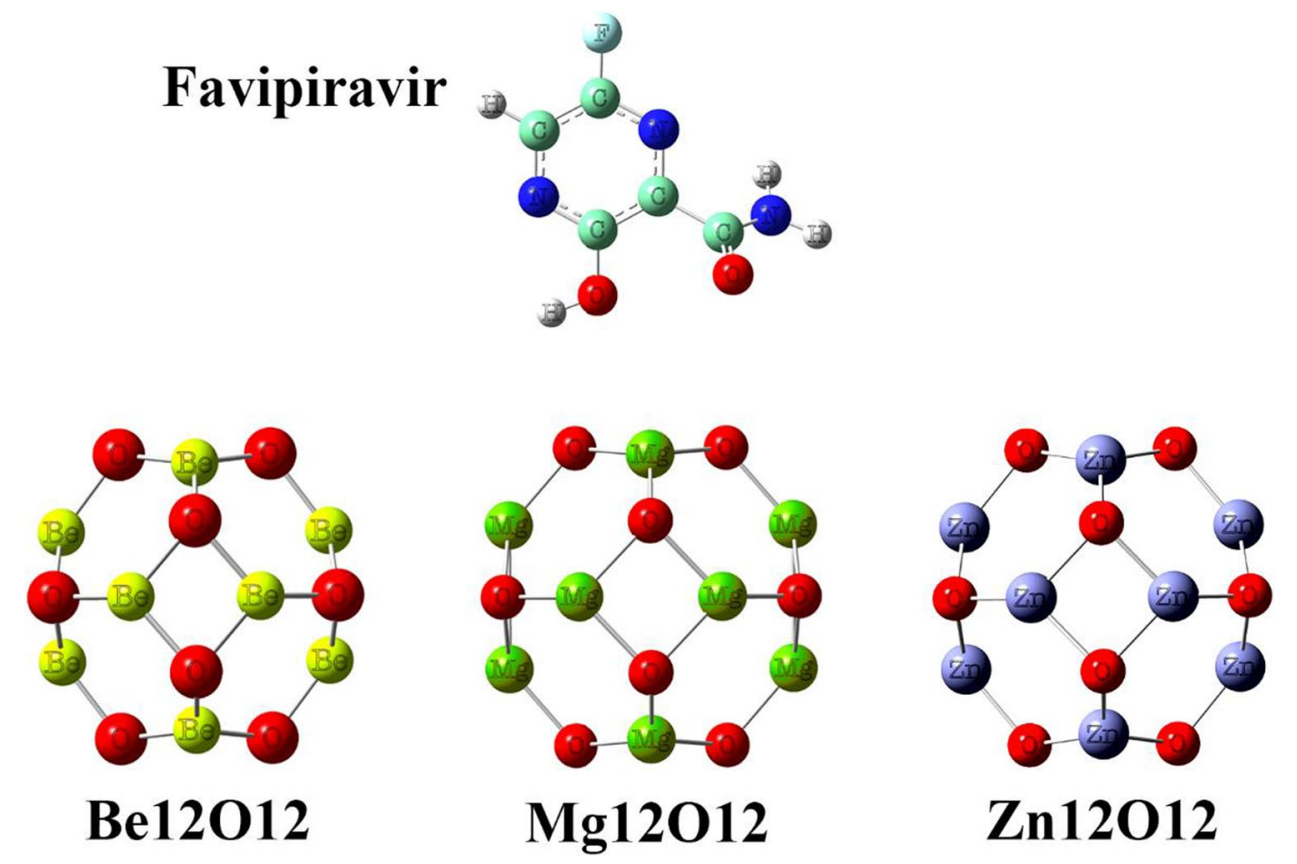

In order to determine if the expected (MO) ${ }_{12} \mathrm{NCs}$ could be experimentally manufactured, the cohesive energy $\mathrm{E}_{\mathrm{coh}}$ was computed as follows:

$E_{c o h}=\left(E_{t o t}-\sum_{i} n_{i} E_{i}\right) / j$

where $\mathrm{E}_{\text {tot }}$ denotes the overall energy of the NCs is, Ei represents the atomic energy, $\mathrm{ni}$ is the number of type-i atoms ( $\mathrm{i}=\mathrm{Zn}, \mathrm{O}, \mathrm{Be}$, and $\mathrm{Mg}$ ) and $\mathrm{j}$ is the number of the total atoms of $(\mathrm{MO})_{12}$. It was necessary to quantify the energy gap $\left(\mathrm{E}_{\mathrm{g}}\right)$ of the lowest and highest occupied molecular orbitals in order to assess Favipiravir adsorption contributions to NC electrical characteristics (LUMO and HOMO). Natural bond orbital (NBO) analysis of charge was used to assess charge transfer between drug molecules and NCs [62]. AIMALL was also used to create QTAIM and better understand the complexes' interactions [63].

\section{Results and discussion}

\section{Structural and electronic characteristics of intact (MO) ${ }_{12} \mathrm{NCs}$}

The intact (MO) 12 and optimized Favipiravir structures are shown in Fig. 1. As can be observed, the intact NCs have six tetragons and eight hexagons with symmetry of Th. $(\mathrm{MgO})_{12},(\mathrm{BeO})_{12}$, and $(\mathrm{ZnO})_{12}$ have the angles of a hexagon (tetragon) of 114.2 (86.6), 111.8 (80.8), and 108.6 (86.9) degrees, respectively. Two forms of $\mathrm{M}-\mathrm{O}$ bonds exist 
in the NCs: a hexagonal double bond (d1) as well as bonds shared by a hexagon and a tetragon (d2). The bond sizes of $\mathrm{d} 1 \mathrm{(d} 2)$ of $(\mathrm{BeO})_{12},(\mathrm{MgO})_{12}$, and $(\mathrm{ZnO})_{12}$, respectively, are 1.54(1.60), 1.88(1.95), and 1.89(1.99) §. The current study used the calculations of harmonic vibrational frequency at the level of the theory of PBE/6-31+g(d) to guarantee that the structures corresponded to energy minima. On the surface of potential energy, the structures were discovered to be real stationary points. $(\mathrm{BeO})_{12},(\mathrm{MgO})_{12}$, and $(\mathrm{ZnO})_{12}$ have harmonic frequencies of $200.6-1194.1 \mathrm{~cm}^{-1}$, $100.6-764.2 \mathrm{~cm}^{-1}$, and $74.8-650.2 \mathrm{~cm}^{-1}$, respectively. The results are consistent with those of $\mathrm{Li}$ and coworkers [64], who investigated NC acetone sensitivity. The NC electrostatic potential (ESP) graphs are shown in Fig. 2, with the red negative regions representing relative charge buildup and the blue positive regions representing charge depletion.

Based on Fig. 2, the best attraction locations for nucleophilic agents are $\mathrm{Be}, \mathrm{Mg}$, and $\mathrm{Zn}$ atoms.

The top perspective for intact NCs' frontier molecular orbital (FMO) is also shown in Fig. 2. As can be observed, the NC HOMOs were discovered to have a preferential distribution on $\mathrm{O}$ atoms.

Fig. 2 The analysis of ESP and the LUMO and HOMO of the intact $(\mathrm{MO})_{12} \mathrm{NCs}$
As a consequence of the FMO findings, the optimum nucleophilic agent attraction regions of the $\mathrm{Be}, \mathrm{Mg}$, and $\mathrm{Zn}$ atoms were discovered.

The NCs were evaluated using the NBO method. The atomic charges of $\mathrm{NBO}$ on the $\mathrm{Be}, \mathrm{Mg}$, and $\mathrm{Zn}$ atoms were shown to be $+1.16,+1.16$, and +1.32 e, respectively, indicating a considerable charge transfer from the mentioned atoms to the $\mathrm{O}$ atom. $\mathrm{E}_{\mathrm{coh}}$ was also computed using Eq. (1), proving that the expected nanoclusters could be manufactured experimentally. For $\mathrm{Be}_{12} \mathrm{O}_{12}, \mathrm{Zn}_{12} \mathrm{O}_{12}$, and $\mathrm{Mg}_{12} \mathrm{O}_{12}$, $\mathrm{E}_{\mathrm{coh}}$ was determined to be - 7.25,-5.55, and $-5.76 \mathrm{eV}$, respectively. According to the findings, $(\mathrm{BeO})_{12}$ has a lower $\mathrm{E}_{\mathrm{coh}}$ than $(\mathrm{MgO})_{12}$ and $(\mathrm{ZnO})_{12}$, implying that $(\mathrm{BeO})_{12}$ might be simpler to produce than $(\mathrm{MgO})_{12}$ and $(\mathrm{ZnO})_{12}$. For $(\mathrm{BeO})_{12},(\mathrm{MgO})_{12}$, and $(\mathrm{ZnO})_{12}, \mathrm{E}_{\mathrm{g}}$ was shown to be $7.23,3.85$, and $2.13 \mathrm{eV}$, respectively. The $\mathrm{E}_{\mathrm{g}}$ findings were inconsistent with previous research [64]. The DOS findings are shown in Fig. 3 so that the influence of the $\mathrm{M}$ atom on the NC electronic characteristics can be checked. Large differences emerged towards the Fermi level, as can be shown, due to significant interactions of $\mathrm{M}-\mathrm{O}$ on both sides. In addition, the valence level for $(\mathrm{ZnO})_{12}$ increases in energy as the
HOMO
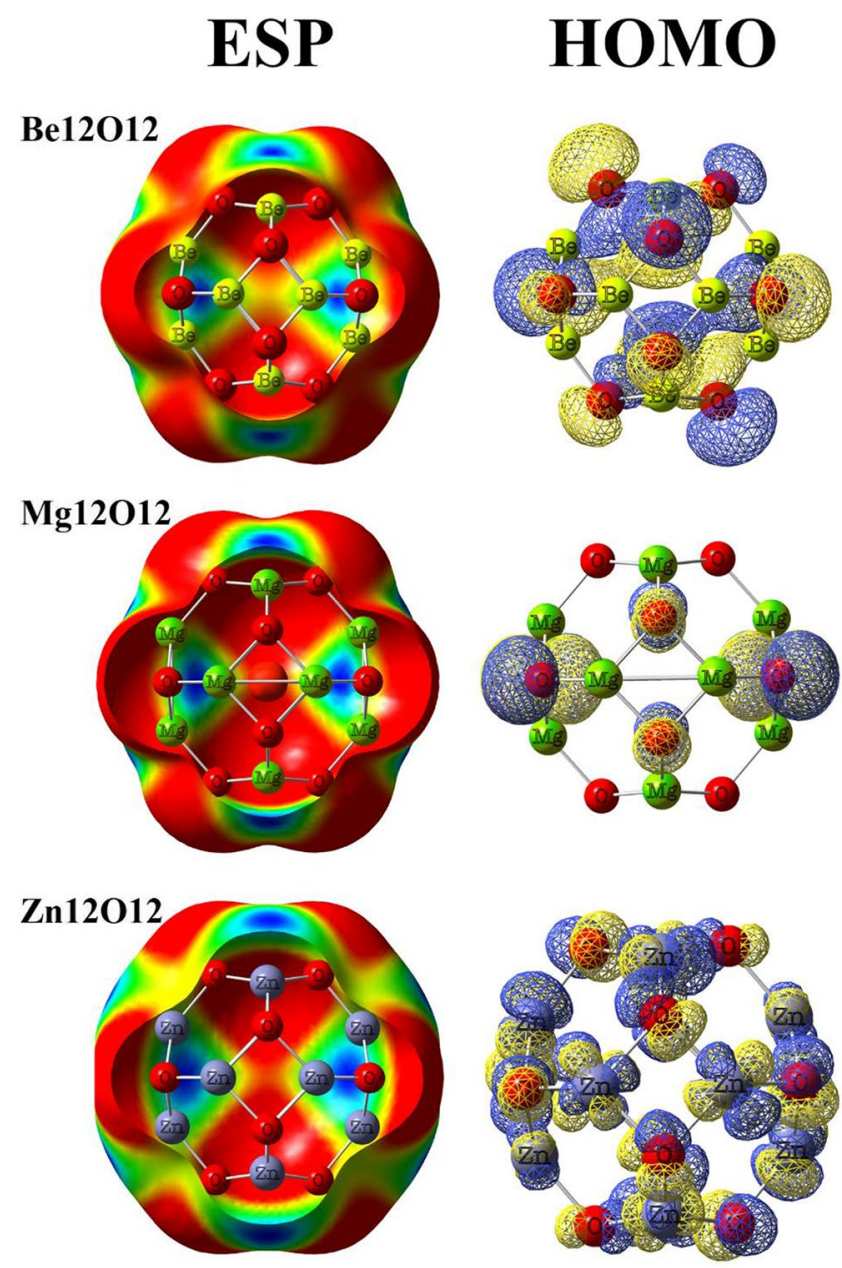

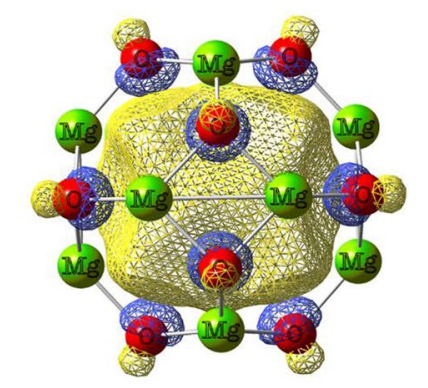

LUMO
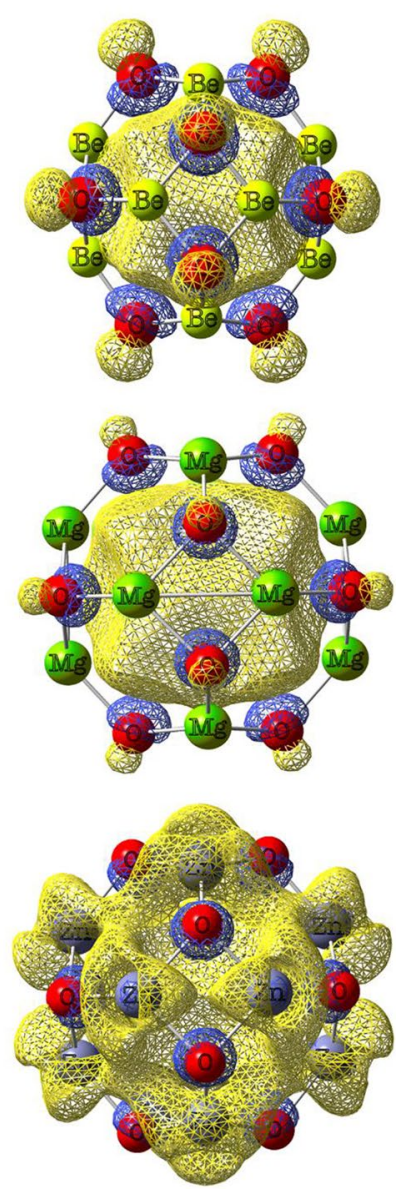

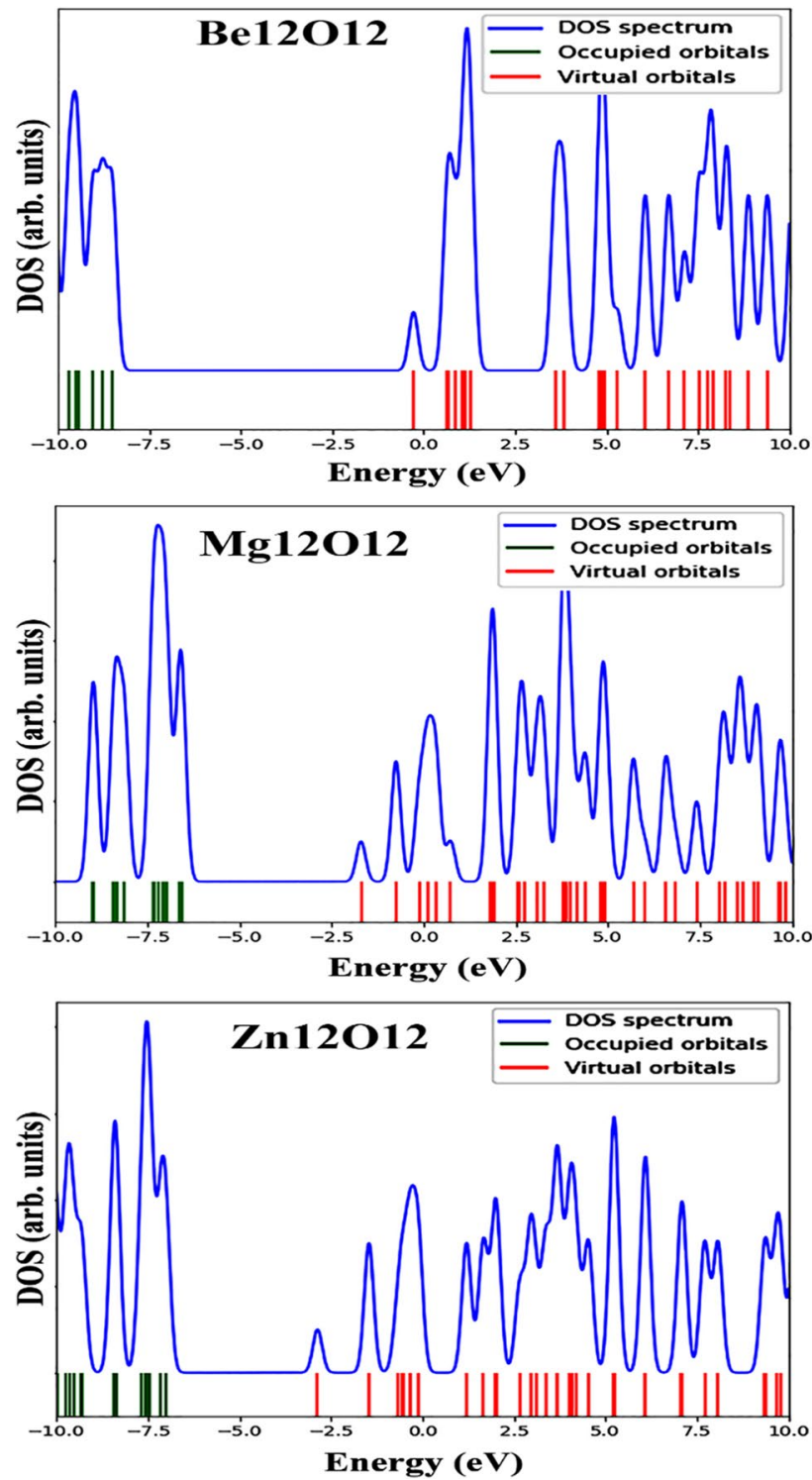

Fig. 3 DOS diagrams for the intact (MO) 12 NCs

conduction level decreases. $\mathrm{E}_{\mathrm{g}}$ is significantly reduced as a result of this. As a result, $(\mathrm{ZnO})_{12}\left(\mathrm{E}_{\mathrm{g}}=2.13 \mathrm{eV}\right)$ may be classified as a semiconductor nanoparticle, while $(\mathrm{BeO})_{12}$ $\left(\mathrm{E}_{\mathrm{g}}=7.23 \mathrm{eV}\right)$ and $(\mathrm{MgO})_{12}\left(\mathrm{E}_{\mathrm{g}}=3.85 \mathrm{eV}\right)$ are often metal oxides that have been insulated.

\section{Favipiravir adsorption on the (MO) 12 NCs}

\section{Energetic evaluation}

The current study looked at a range of configurations to find the most stable adsorption on the NC surface, such as placing Favipiravir oxygen, nitrogen, and fluorine atoms at various positions, such as the tops of $\mathrm{Mg}, \mathrm{Zn}, \mathrm{O}$, and $\mathrm{Be}$ atoms, as well as the tetragonal and hexagonal ring centers. $E_{a d s}$, the

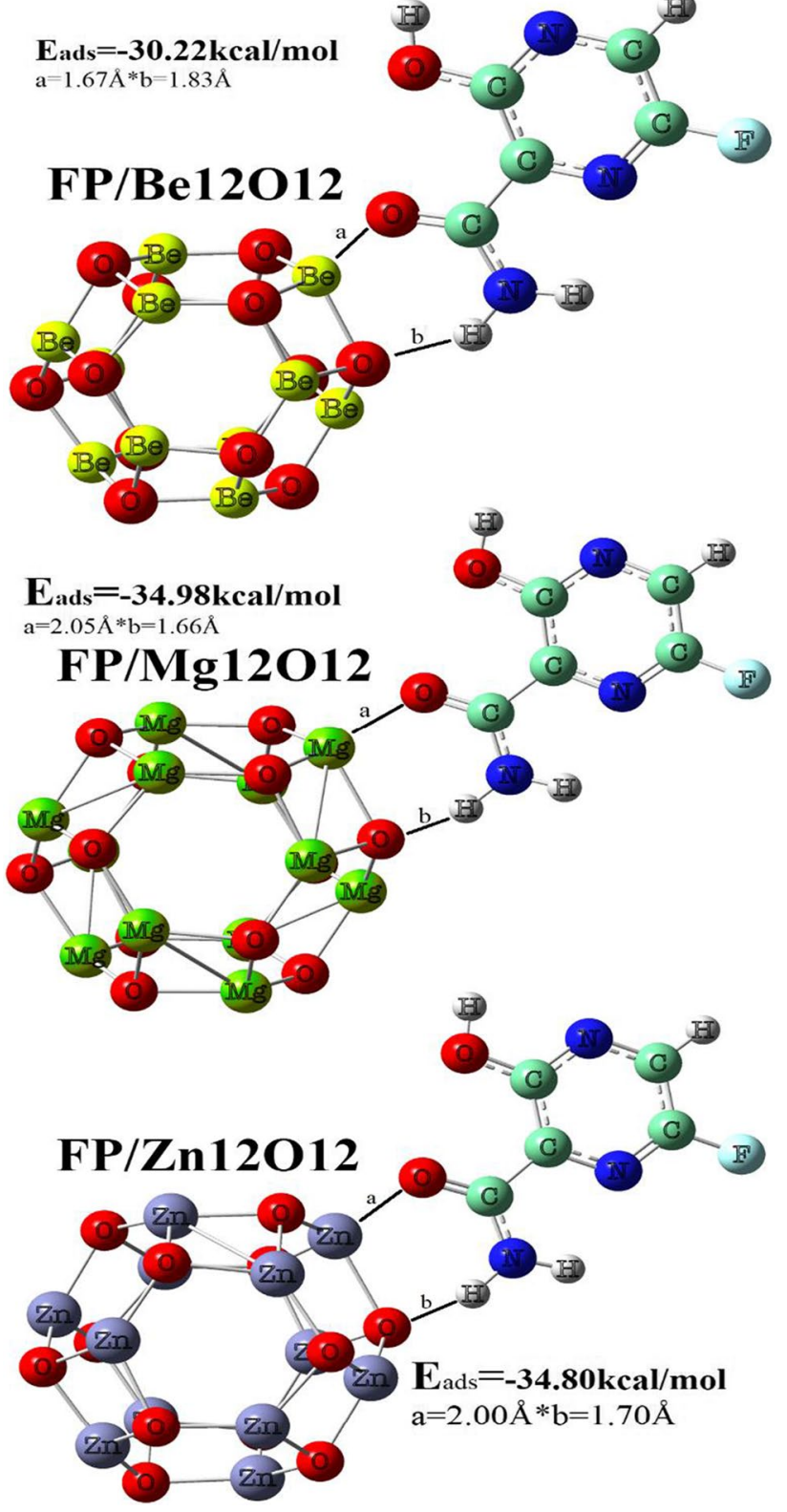

Fig. 4 The most stable electronic configurations of the adsorbed Favipiravir on $(\mathrm{MO})_{12} \mathrm{NCs}$ ' surface

shortest NC-drug distance, and the most stable electronic configurations are shown in Fig. 4. Based on Fig. 4, the optimized-geometry Favipiravir has the maximum propensity for $\mathrm{O}$ and $\mathrm{M}$ atom interaction. This is in line with the ESP and FMO findings. The interaction distances of the Favipiravir $/ \mathrm{Be}_{12} \mathrm{O}_{12}$, Favipiravir $/ \mathrm{Zn}_{12} \mathrm{O}_{12}$, and Favipiravir $/ \mathrm{Mg}_{12} \mathrm{O}_{12}$ complexes are also shown in Fig. 4. As can be observed, the interaction distances between Favipiravir $/ \mathrm{Zn}_{12} \mathrm{O}_{12}$ and Favipiravir $/ \mathrm{Mg}_{12} \mathrm{O}_{12}$ are quite short. As a consequence, it is safe to assume that chemisorption will take place.

The adsorption energies of $(\mathrm{BeO})_{12},(\mathrm{ZnO})_{12}$, and $(\mathrm{MgO})_{12}$ were shown to interact with Favipiravir 
Table 1 Comparison of the values of Eads ( $\mathrm{kcal} / \mathrm{mol}$ ) obtained in the solution and gas phase for the complexes of Favipiravir/(MO)12

\begin{tabular}{lll}
\hline Molecule & Gas phase & Solution \\
\hline Favipiravir $/ \mathrm{Be}_{12} \mathrm{O}_{12}$ & -30.22 & -41.11 \\
Favipiravir $/ \mathrm{Mg}_{12} \mathrm{O}_{12}$ & -34.98 & -46.65 \\
Favipiravir $/ \mathrm{Zn}_{12} \mathrm{O}_{12}$ & -34.80 & -47.75 \\
\hline
\end{tabular}

at $-30.22,-34.80$, and $-34.98 \mathrm{kcal} / \mathrm{mol}$, respectively. Since Favipiravir adsorptions onto $(\mathrm{ZnO})_{12}$ and $(\mathrm{MgO})_{12}$ have great adsorption energy levels, the Favipiravir molecule is chemisorbed onto the nanocluster. The lower interaction lengths between the drug $\mathrm{O}$ and $\mathrm{H}$ atoms and the nanocluster $\mathrm{O}$ and $\mathrm{M}$ atoms explain this. As a consequence, it can be stated that $(\mathrm{MgO})_{12}$ and $(\mathrm{ZnO})_{12}$ are more suitable for Favipiravir adsorption. These results are in good agreement with the ESP, NBO, and FMO reactivity patterns. The largest positive charge on the $\mathrm{M}$ atom as the best attraction site of the nucleophilic agent is represented by the $\mathrm{E}_{\text {ads }}$ maximum level of Favipiravir/(MO) ${ }_{12}$

The current study looked at the influence of a solvent on Favipiravir adsorption onto NCs in aqueous conditions. The polarizable continuum model was used to quantify the influence of water as the solvent $(\varepsilon=78.4)$. According to the results of $\mathrm{E}_{\mathrm{ads}}$, the complexes were compared in aqueous and gaseous phases (Table 1). As can be observed, the energy levels in both phases are fully negative, indicating that the complexes are stable. The greater the possible solubility of the NC to affect the Favipiravir-NC interaction, the larger the absolute amount of negative adsorption energy in the aqueous phase. The DOS data are shown in Fig. 5 to validate the impacts of Favipiravir on $\mathrm{NC}$ electronic characteristics. As shown in Fig. 6, $(\mathrm{MgO})_{12}$ and $(\mathrm{ZnO})_{12}$ displayed minor postFavipiravir adsorption modifications in LUMO and HOMO. As a result, $\mathrm{E}_{\mathrm{g}}$ stayed almost unaltered. The valence (conduction) level of Favipiravir/(BeO) ${ }_{12}$, on the other hand, rose (reduced). As a consequence, the $\mathrm{E}_{\mathrm{g}}$ of $(\mathrm{BeO})_{12}$ was smaller than that of its immaculate equivalent.

\section{UV-Vis spectra}

At the level of the theory of PBE/6-31+g(d), the UV-Vis spectrum of both pure NCs and Favipiravir-nanocluster complexes were measured. Table 2 lists the important transitions (i.e., the greatest oscillator strengths (f)). Based on Table 2, the greatest adsorption wavelengths of the intact $(\mathrm{BeO})_{12}$, $(\mathrm{ZnO})_{12}$, and $(\mathrm{MgO})_{12}$ were determined to be 294.72, 372.36 , and $411.45 \mathrm{~nm}$, respectively. The greatest oscillator strengths were $0.1241,0.0032$, and 0.0035 , respectively. The majority of adsorption wavelength peaks are explained by $\mathrm{HOMO} \rightarrow$ LUMO transitions. The intact $\mathrm{NC}$ adsorption bands dropped to higher wavelengths when Favipiravir was
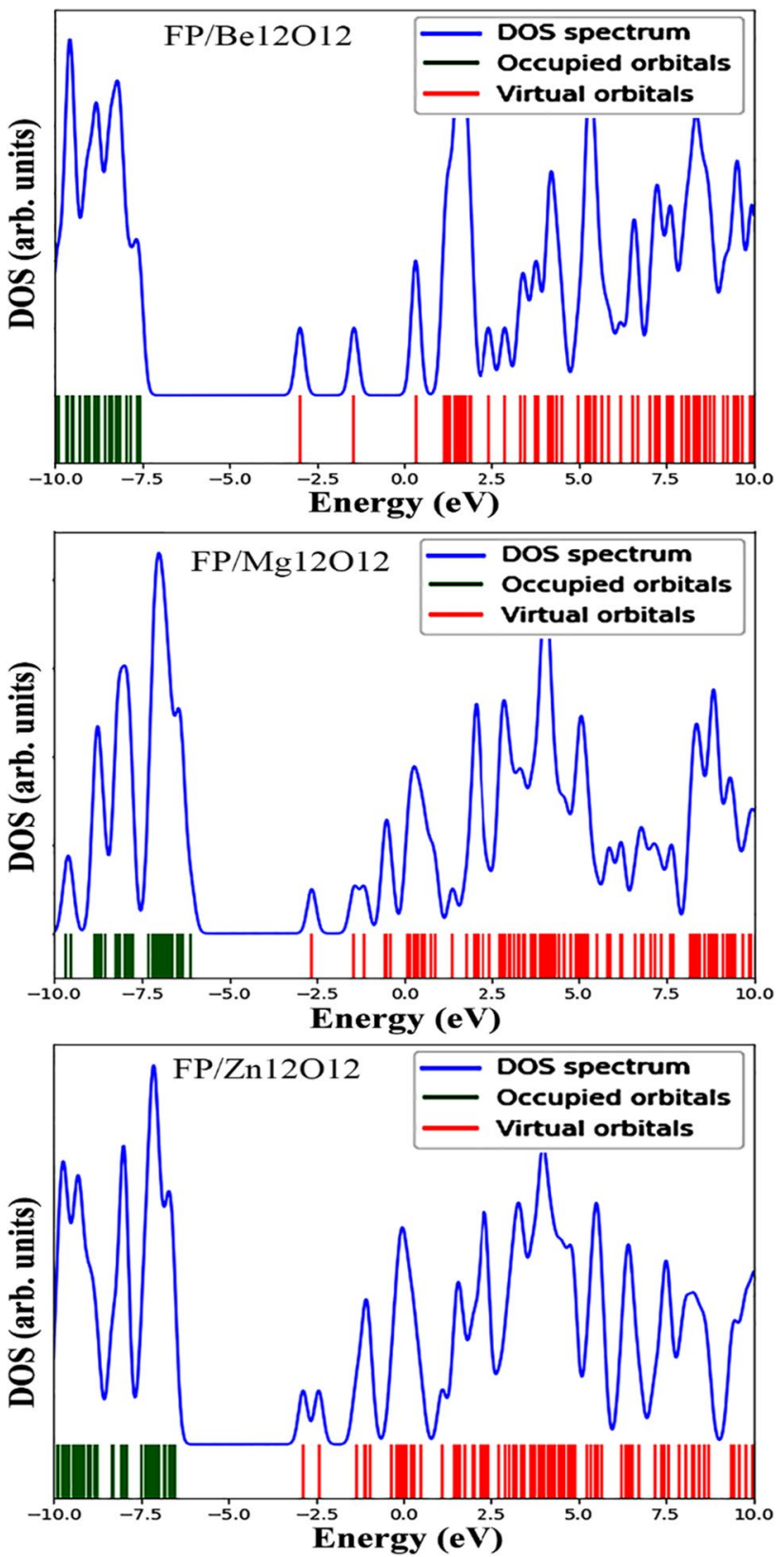

Fig. 5 DOS diagrams for Favipiravir/(MO)12 compounds

adsorbed onto them. Thus, it is possible to deduce that the electronic spectrum of the complexes experiences a redshift to higher wavelengths. The most significant redshift was seen in Favipiravir/(BeO) ${ }_{12}(126 \mathrm{~nm})$.

\section{AIM analysis}

AIM is a capable tool for determining the interactions between molecules. AIM can identify the bond critical points (BCPs) between interactive systems using topologi$\mathrm{cal}$ variables. The improved Favipiravir/NC complexes are shown as molecular graphs in Fig. 6. Based on Table 2, at 
Fig. 6 Molecular diagram of Favipiravir/(MO)12 compounds. Bond pathways are shown by the lines

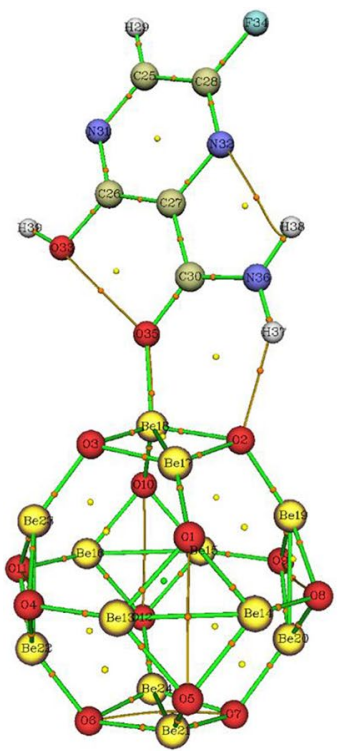

FP/Be12O12
Table 2 The estimated maximum value of absorption wavelength $(\lambda)$, the transition of dominant contribution for the intact (MO) 12 and Favipiravir/(MO)12 and complexes, and oscillator strengths (f)

\begin{tabular}{llll}
\hline complexes & $\lambda(\mathrm{nm})$ & $\mathrm{f}_{0}$ & Major contribution \\
\hline $\mathrm{Be}_{12} \mathrm{O}_{12}$ & 168.21 & 0.0024 & $\mathrm{HOMO} \rightarrow$ LUMO $(71 \%)$ \\
Favipiravir/ $\mathrm{Be}_{12} \mathrm{O}_{12}$ & 294.72 & 0.1241 & $\mathrm{HOMO} \rightarrow$ LUMO $(74 \%)$ \\
$\mathrm{Mg}_{12} \mathrm{O}_{12}$ & 300.31 & 0.0049 & $\mathrm{HOMO} \rightarrow$ LUMO $(71 \%)$ \\
Favipiravir $/ \mathrm{Mg}_{12} \mathrm{O}_{12}$ & 411.45 & 0.0035 & $\mathrm{HOMO} \rightarrow$ LUMO $(76 \%)$ \\
$\mathrm{Zn}_{12} \mathrm{O}_{12}$ & 348.98 & 0.0093 & $\mathrm{HOMO} \rightarrow$ LUMO $(70 \%)$ \\
Favipiravir/ $\mathrm{Zn}_{12} \mathrm{O}_{12}$ & 372.36 & 0.0032 & $\mathrm{HOMO} \rightarrow$ LUMO $(75 \%)$ \\
\hline
\end{tabular}

BCPs, the computed values of $\rho c$ for the complexes range from 0.0341 to 0.0762 a.u. The $\nabla^{2} \rho c$ values also range from 0.0542 to 0.145 a.u. The $\rho c$ values are raised when $\mathrm{Mg}$ and $\mathrm{Zn}$ atoms replace the NC's M atom (Table 3).

The high charge densities of the $\mathrm{O}-\mathrm{H}$ and $\mathrm{M}-\mathrm{O}$ bonds, as well as a positive $\nabla^{2} \rho c$, are suggested by the electron density features of the complexes. As a consequence, the electrostatic properties of $\mathrm{O}-\mathrm{H}$ and $\mathrm{M}-\mathrm{O}$ bonding may be stated to be reasonable. Indeed, a partly covalent connection is represented by a positive $\nabla^{2} \rho c$ and negative $\mathrm{HC}$, while

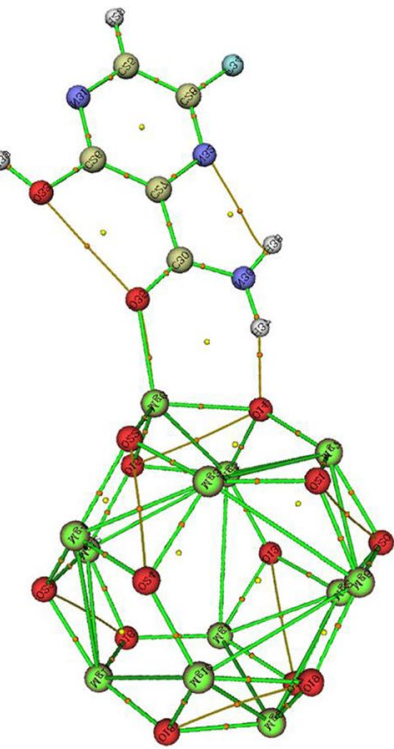

FP/Mg12O12

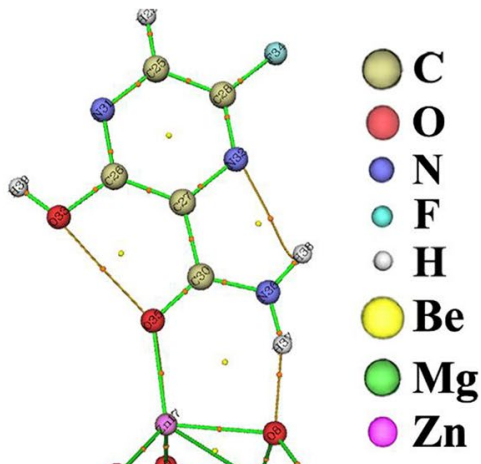

an electrostatic interaction is represented by a positive HC. Thus, the studied compounds showed positive $\nabla 2 \rho \mathrm{c}$ and negative $\mathrm{HC}$, indicating polar covalent $\mathrm{Be}-\mathrm{O}, \mathrm{Zn}-\mathrm{O}$, and Mg-O bonds.

Based on Table 2, the Favipiravir/( $\mathrm{MgO})_{12}$ and Favipiravir/ $(\mathrm{ZnO})_{12}$ complexes showed high values, indicating strong Be-O, Zn-O, and Mg-O interactions. The Eads, FMO, and ESP findings accord with the AIM findings of these complexes.

\section{Conclusions}

The Favipiravir drugs' adsorption onto fullerene-like (MO) $)_{12}$ NCs was investigated in this work. A study of the NC's adsorption energies revealed that $(\mathrm{MgO})_{12}$ and $(\mathrm{ZnO})_{12}$ could significantly increase Favipiravir drugs' adsorption on the NCs. Favipiravir/ $\mathrm{Be}_{12} \mathrm{O}_{12}\left(30.22 \mathrm{kcal} \mathrm{mol}^{-1}\right)$, Favipiravir/ $/ \mathrm{Zn}_{12} \mathrm{O}_{12}\left(34.80 \mathrm{kcal} \mathrm{mol}^{-1}\right)$, and Favipiravir/Mg12O12 (34.98 $\left.\mathrm{kcal} \mathrm{mol}^{-1}\right)$ were rated in order of drug adsorption degrees. As a result, Favipiravir attachment to $(\mathrm{MgO})_{12}$ and $(\mathrm{ZnO})_{12}$ might be simple, increasing Favipiravir loading efficiency. In addition, the QTAIM assessment was used to
Table 3 The Laplacian of electron density $(\nabla 2 \rho)$, electron density $(\rho)$, total electron energy density $(\mathrm{H})$ in a.u., potential energy density $(\mathrm{V})$, kinetic energy density $(\mathrm{K})$, and at BCPs in the Favipiravir-adsorbed compounds by AIM analysis

\begin{tabular}{llllllll}
\hline Complexes & $\mathrm{BCP}$ & $\nabla 2 \rho$ & $\rho$ & $\mathrm{K}(\mathrm{r})$ & $\mathrm{V}(\mathrm{r})$ & $\mathrm{H}(\mathrm{r})$ & $\mathrm{K}(\mathrm{r}) / \mathrm{V}(\mathrm{r}) \mid$ \\
\hline Favipiravir/ $/ \mathrm{Be}_{12} \mathrm{O}_{12}$ & $\mathrm{Be}_{18}-\mathrm{O}_{35}$ & 0.431 & 0.0601 & -0.0067 & -0.0944 & -0.0067 & 0.0709 \\
& $\mathrm{O}_{2}-\mathrm{H}_{37}$ & 0.109 & 0.0341 & 0.0010 & -0.029 & -0.0010 & 0.0344 \\
Favipiravir/ $/ \mathrm{Mg}_{12} \mathrm{O}_{12}$ & $\mathrm{Mg}_{6}-\mathrm{O}_{35}$ & 0.269 & 0.0360 & -0.0110 & -0.0452 & -0.0110 & 0.2433 \\
& $\mathrm{O}_{14}-\mathrm{H}_{36}$ & 0.154 & 0.0522 & 0.0032 & -0.0451 & -0.0032 & 0.0709 \\
Favipiravir/Zn $/ \mathrm{Zn}_{12} \mathrm{O}_{12}$ & $\mathrm{Zn}_{17}-\mathrm{O}_{35}$ & 0.319 & 0.0762 & 0.0251 & -0.1303 & -0.0251 & 0.1926 \\
& $\mathrm{O}_{8}-\mathrm{H}_{37}$ & 0.145 & 0.0470 & 0.0025 & -0.0413 & -0.0025 & 0.0605 \\
\hline
\end{tabular}


look at the interactions between molecules. The Eads, FMO, NBO, and ESP reactivity patterns were shown to be in excellent agreement with the QTAIM data. The electrostatic properties of the system with the biggest positive charge on the $\mathrm{M}$ atom and the largest Eads were shown to be the best. This system was shown to be the best attraction site for nucleophilic agents. The findings show that $(\mathrm{MgO})_{12}$ and $(\mathrm{ZnO})_{12}$ have great carrier potential and may be used in medication delivery. However, more in vivo research is needed to confirm these findings.

Author contribution Chunchun Yao: Supervision, writing-original draft, writing - review \& editing

Feng Xiang: software, methodology

Zhangyi Xu: conceptualization, investigation, project administration

\section{Availability of data and material N/A.}

Code availability N/A.

\section{Declarations}

Conflict of interest The authors declare no competing interests.

\section{References}

1. Lipsitch M, Swerdlow DL, Finelli L (2020) Defining the epidemiology of Covid-19-studies needed. New England journal of medicine, 382(13):1194-1196.

2. Sun ML, Yang JM, Sun YP, Su GH (2020) Inhibitors of RAS might be a good choice for the therapy of COVID-19 pneumonia. Chin J Tubercul Respirator Dis 43:E014

3. Hatada0 R, Okuwak K, Mochizuki Y, Handa Y, Fukuzawa K, Komeiji Y, Tanaka S (2020) Fragment molecular orbital based interaction analyses on COVID-19 main proteaseinhibitor N3 complex (PDB ID: 6LU7). J Chem Info Model 60(7):3593-3602

4. Wang KY, Liu F, Jiang R, Yang X, You T, Liu X, Rao Z (2020) Structure of Mpro from COVID-19 virus and discovery of its inhibitors. Nature 582:289-293

5. Cai Q, Yang M, Liu D, Chen J, Shu D, Xia J, Liu L (2020) Experimental treatment with favipiravir for COVID-19: an open-label control study. Eng 6(10):1192-1198

6. Juárez AR, Ortiz-Chi F, Pino-Ríos R, Cárdenas-Jirón G, Villanueva MS, Anota EC (2020) The boron nitride (B116N124) fullerene: Stability and electronic properties from DFT simulations. Chem Phys Lett 741:137097

7. Juárez AR, Ortiz-Chi F, Borges-Martinez M, Cardenas-Jiron G, Villanueva MS, Anota EC (2019) Stability, electronic and optical properties of the boron nitride cage (B47N53) from quantum mechanical calculations. Physica E 111:118-126

8. Anota EC, Villanueva MS, Shakerzadeh E, Castro M (2018) Adsorption and possible dissociation of glucose by the [BN fullerene-B 6]- magnetic nanocomposite. In silico stud Appl Nanosci 8(3):455-465

9. dos Santos RB, Rivelino R, de Mota FB, Gue-orguiev GK (2012) J Phys Chem A 116:9080
10. Rivelino R, Dos Santos RB, de Brito Mota F, Gueorguiev GK (2010) Conformational effects on structure, electron states, and Raman scattering properties of linear carbon chains terminated by graphene-like pieces. J Phys Chem C 114(39):16367-16372

11. Dos Santos RB, de Brito Mota F, Rivelino R, Kakanakova-Georgieva A, Gueorguiev GK (2016) Van der Waals stacks of few-layer h-AlN with graphene: an ab initio study of structural, interaction and electronic properties. Nanotechnology 27(14):145601

12. Rostami Z, Soleymanabadi H (2017) Investigation of phosgene adsorption behavior on aluminum nitride nanocones: Density functional study. J Mol Liq 248:473-478

13. Noei M, Soleymanabadi H, Peyghan AA (2017) Aluminum nitride nanotubes. Chem Pap 71(5):881-893

14. Jameh-Bozorghi S, Soleymanabadi H (2017) Warped C80H30 nanographene as a chemical sensor for CO gas: DFT studies. Phys Lett A 381(6):646-651

15. Rastgou A, Soleymanabadi H, Bodaghi A (2017) DNA sequencing by borophene nanosheet via an electronic response: a theoretical study. Microelectron Eng 169:9-15

16. Hosseini J, Bodaghi A, Soleymanabadi H (2017) A DFT study on graphyne fluorination. Russ J Phys Chem A 91(1):116-123

17. Rostami Z, Soleymanabadi H (2016) N-H bond cleavage of ammonia on graphene-like B 36 borophene: DFT studies. J Mol Model 22(4):70

18. Vahabi V, Soleymanabadi H (2016) A quantum mechanical analysis of the electronic response of BN nanocluster to formaldehyde. J Mex Chem Soc 60(1):34-39

19. Rastegar SF, Soleymanabadi H, Bagheri Z (2015) Physisorption to chemisorption transition of $\mathrm{H} 2 \mathrm{~S}$ on carbon nanocone induced by decoration of Be 2 O 2 cluster. J Iran Chem Soc 12(6):1099-1106

20. Peyghan AA, Soleymanabadi H, Bagheri Z (2015) Theoretical study of carbonyl sulfide adsorption on Ag-doped SiC nanotubes. J Iran Chem Soc 12(6):1071-1076

21. Peyghan AA, Soleymanabadi H (2015) Computational study on ammonia adsorption on the $\mathrm{X} 12 \mathrm{Y} 12$ nano-clusters $(\mathrm{X}=\mathrm{B}, \mathrm{Al}$ and $\mathrm{Y}=\mathrm{N}, \mathrm{P}$ ). Curr Sci 1910-1014

22. Rastegar SF, Peyghan AA, Soleymanabadi H (2015) Ab initio studies of the interaction of formaldehyde with beryllium oxide nanotube. Physica E 68:22-27

23. Hadipour NL, Ahmadi Peyghan A, Soleymanabadi H (2015) Theoretical study on the Al-doped $\mathrm{ZnO}$ nanoclusters for $\mathrm{CO}$ chemical sensors. J Phys Chem C 119(11):6398-6404

24. Nayebzadeh M, Soleymanabadi H, Bagheri Z (2014) Adsorption and dissociation of nitrous oxide on pristine and defective $\mathrm{BeO}$ and $\mathrm{ZnO}$ nanotubes: DFT studies. Monatshefte für Chemie-Cheml Mon 145(11):1745-1752

25. Nayebzadeh M, Peyghan AA, Soleymanabadi H (2014) Density functional study on the adsorption and dissociation of nitroamine over the nanosized tube of MgO. Physica E 62:48-54

26. Peyghan AA, Aslanzadeh SA, Soleymanabadi H (2014) Methanolsensing characteristics of zinc oxide nanotubes: quantum chemical study. Monatshefte für Chemie-Chem Mon 145(8):1253-1257

27. Soleymanabadi H, Kakemam J (2013) A DFT study of H2 adsorption on functionalized carbon nanotubes. Physica E 54:115-117

28. Soleymanabadi H, Peyghan AA (2013) Decomposition of methanol on nanosized tube of magnesium oxide: a theoretical study. Comput Mater Sci 79:182-186

29. Peyghan AA, Soleymanabadi H, Moradi M (2013) Structural and electronic properties of pyrrolidine-functionalized [60] fullerenes. J Phys Chem Solids 74(11):1594-1598

30. Rastegar SF, Hadipour NL, Tabar MB, Soleymanabadi H (2013) DFT studies of acrolein molecule adsorption on pristine and Aldoped graphenes. J Mol Model 19(9):3733-3740

31. Beheshtian J, Soleymanabadi H, Peyghan AA, Bagheri Z (2013) A DFT study on the functionalization of a $\mathrm{BN}$ nanosheet with 
$\mathrm{PCX},(\mathrm{PC}=$ phenyl carbamate, $\mathrm{X}=\mathrm{OCH} 3, \mathrm{CH} 3, \mathrm{NH} 2, \mathrm{NO} 2$ and CN). Appl Surf Sci 268:436-441

32. Beheshtian J, Soleymanabadi H, Kamfiroozi M, Ahmadi A (2012) The $\mathrm{H} 2$ dissociation on the $\mathrm{BN}, \mathrm{AlN}, \mathrm{BP}$ and AlP nanotubes: a comparative study. J Mol Model 18(6):2343-2348

33. Mao Y, Soleymanabadi H (2020) Graphyne as an anode material for Mg-ion batteries: A computational study. J Mol Liquids 308:113009

34. Li M, Wei Y, Zhang G, Wang F, Li M, Soleymanabadi H (2020) A DFT study on the detection of isoniazid drug by pristine, $\mathrm{Si}$ and Al doped C70 fullerenes. Physica E: Low-dimensional Systems and Nanostructures 118, 113878.

35. Wu X, Zhang Z, Soleymanabadi H (2020) Substituent effect on the cell voltage of nanographene based Li-ion batteries: a DFT study. Solid State Commun 306:113770

36. Goudarziafshar H, Abdolmaleki M, Moosavi-zare AR, Soleymanabadi $\mathrm{H}$ (2018) Hydrogen storage by Ni-doped silicon carbide nanocage: a theoretical study. Physica E 101:78-84

37. Amirkhani R, Omidi MH, Abdollahi R, Soleymanabadi H (2018) Investigation of sarin nerve agent adsorption behavior on $\mathrm{BN}$ nanostructures: DFT study. J Cluster Sci 29(4):757-765

38. Moosavi-zare AR, Abdolmaleki M, Goudarziafshar H, Soleymanabadi H (2018) Adsorption behavior of amphetamine on the inorganic BC3 nanotube and nanosheet: DFT studies. Inorg Chem Commun 91:95-101

39. Saedi L, Maskanati M, Modheji M, Soleymanabadi H (2018) Tuning the field emission and electronic properties of silicon nanocones by $\mathrm{Al}$ and $\mathrm{P}$ doping: DFT studies. J Mol Graph Model $81: 168-174$

40. Wang P, Wang SZ, Kang YR, Sun ZS, Wang XD, Meng Y, Xie WF (2021) Cauliflower-shaped $\mathrm{Bi} 2 \mathrm{O} 3-\mathrm{ZnO}$ heterojunction with superior sensing performance towards ethanol. J Alloys Compounds 854:157152

41. Yang Y, Liu J, Zhou X (2021) A CRISPR-based and post-amplification coupled SARS-CoV-2 detection with a portable evanescent wave biosensor. Biosens Bioelectron 190:113418. https://doi.org/ 10.1016/j.bios.2021.113418

42. Zhang T, Wang Z, Xiang H, Xu X, Zou J, Lu C (2021) Biocompatible superparamagnetic Europium-doped iron oxide nanoparticle clusters as multifunctional nanoprobes for multimodal in vivo imaging. ACS Appl Mater Interfaces 13(29):33850-33861. https://doi.org/10.1021/acsami.1c07739

43. Zong X, Xiao X, Shen B, Jiang Q, Wang H, Lu Z, Wang Y (2021) The N6-methyladenosine RNA-binding protein YTHDF1 modulates the translation of TRAF6 to mediate the intestinal immune response. Nucleic Acids Res 49(10):5537-5552. https://doi.org/ 10.1093/nar/gkab343

44. Shuja KH, Aqeel M, Jaffar A, Ahmed A (2020) COVID-19 pandemic and impending global mental health implications. Psychiatr Danub 32(1):32-35. https://doi.org/10.24869/psyd.2020.32

45. Ogutlu H, Esin IS, Erdem HB, Tatar A, Dursun OB (2020) Mitochondrial DNA copy number is associated with attention deficit hyperactivity disorder. Psychiatr Danub 32(2):168-175. https:// doi.org/10.24869/psyd.2020.168

46. Gao T, Li C, Yang M, Zhang Y, Jia D, Ding W, Debnath S, Yu T, Said Z, Wang J (2021) Mechanics analysis and predictive force models for the single-diamond grain grinding of carbon fiber reinforced polymers using CNT nano-lubricant. J Mater Process
Technol 290:116976. https://doi.org/10.1016/j.jmatprotec.2020. 116976

47. Duan Z, Li C, Ding W, Zhang Y, Yang M, Gao T, Cao H, Xu X, Wang D, Mao C (2021) Milling force model for aviation aluminum alloy: academic insight and perspective analysis, Chinese Journal of. Mech Eng 34:1-35

48. Wang Y, Li C, Zhang Y, Yang M, Li B, Dong L, Wang J (2018) Processing characteristics of vegetable oil-based nanofluid MQL for grinding different workpiece materials. Int J Precis Eng and Manuf-Green Technol 5:327-339

49. Yang M, Li C, Zhang Y, Jia D, Li R, Hou Y, Cao H, Wang J (2019) Predictive model for minimum chip thickness and size effect in single diamond grain grinding of zirconia ceramics under different lubricating conditions. Ceram Int 45:14908-14920

50. Huang B, Changhe L, Zhang Y, Wenfeng D, Min Y, Yuying Y, Han Z, Xuefeng X, Dazhong W, Debnath S (2021) Advances in fabrication of ceramic corundum abrasives based on sol-gel process. Chin J Aeronaut 34:1-17. https://doi.org/10.1016/j.cja.2020. 07.004

51. Yin Q, Li C, Dong L, Bai X, Zhang Y, Yang M, Liu Z (2021) Effects of physicochemical properties of different base oils on friction coefficient and surface roughness in MQL milling AISI 1045. Int J Precision Eng Manufacturing-Green Technol 8(6):1629-1647

52. Beheshtian, J., Baei, M. T., Bagheri, Z., \& Peyghan, A. A. (2012). AlN nanotube as a potential electronic sensor for nitrogen dioxide. Microelectronics Journal, 43(7), 452-455.

53. Peyghan AA, Baei MT, Hashemian S (2013) J Cluster Sci 24:341

54. Li J, Lu Y, Ye Q, Cinke M, Han J, Meyyappan M (2003) Carbon nanotube sensors for gas and organic vapor detection. Nano Lett 3:929-933

55. Baei MT, Peyghan AA, Bagheri Z (2012) Chin J Chem Phys 25:671

56. Shakerzdeh E, Tahmasebi E, Shamlouei HR (2015) Synth Met 204:17

57. Shakerzadeh E (2014) J Inorg Organomet Polym Mater 24:694

58. Omidi M, Shamlouei HR, Noormohammad-beigi M (2017) J Mol Model 23:82

59. Hussain S, Grabinski C, Schaeublin N, Maurer E, Garrett C, Sankaran M, Trickler W (2012) Toxicity Evaluation of Engineered Nanomaterials: Portable In Vitro Chamber to Study Realistic Occupational Exposure in Biological Systems (Phase 2 Studies). Air Force Res Lab Wright Patterson AFB Of Human Performance Wing (100th) Human Effectiveness DIR/Bioeffects Division

60. Perdew JP, BurkeandM K, Ernzerhofx (1996) Phys Rev Lett 77:3865

61. Grimme S (2006) J Comput Chem 27:1787

62. Gaussian09 RA (2009) 1, mj frisch, gw trucks, hb schlegel, ge scuseria, ma robb, jr cheeseman, g. Scalmani, v. Barone, b. Mennucci, ga petersson et al., gaussian. Inc., Wallingford CT 121:150-166

63. Reed AE, CurtissandF LA, A Weinhold (1998) Chem Rev 88:899

64. KF Biegler, J Schnbohm, D Bayles (2001) A program to analyze and visualize atoms in molecules

Publisher's Note Springer Nature remains neutral with regard to jurisdictional claims in published maps and institutional affiliations. 